\title{
NEEM BIODIESEL: AN ALTERNATIVE FUEL
}

\section{ABHISHEK RASTOGI, MOHD. SHABAN, SHIVAM SAXENA,'TEJ PRATAP SINGH*}

Department of Chemical Engineering, Bundelkhand Institute of Engineering and Technology, Kanpur Road Jhansi, Uttar Pradesh, India. Email: anshbiet@gmail.com

Received: 03 July 2021, Revised and Accepted: 21 October 2021

ABSTRACT

Objective: Fossil fuels are a major source of energy in today's world but due to the limited availability of fossil fuels and its harmful emissions, it is now very important to shift our focus toward other sources of energy. Biofuels can help us meet this energy requirement. This study is aimed at producing neem biodiesel from neem oil by "transesterification process" using sodium hydroxide $(\mathrm{NaOH})$ and studying its various fuel properties.

Methods: First, extraction was done to produce neem oil from its seeds. Free fatty acid content was reduced and transesterification reaction was carried out at temperature of around $55-65^{\circ} \mathrm{C}$ in the presence of alkali catalyst, $\mathrm{NaOH}$ to produce neem biodiesel. Properties of biodiesel produced such as viscosity and flash point were then determined using redwood viscometer, Abel-Pensky apparatus, and their respective methods for other properties.

Results: Produced neem biodiesel showed higher pour point than that of conventional diesel. Viscosity of neem oil was much higher than standards and was greatly reduced when converted to biodiesel using transesterification and biodiesel showed kinematic viscosity of $5.2 \mathrm{cSt}$ at $35^{\circ} \mathrm{C}$.

Conclusion: Neem biodiesel produced has many fuel properties close to that of conventional diesel. Furthermore, the biodegradable, non-toxic nature of biodiesel is another reason for considering it as an alternative fuel. As we cannot directly use neem oil in diesel engine due to its high viscosity, so it is needed to convert it into biodiesel so that its properties become comparable to the conventional diesel.

Keywords: Neem oil, Transesterification reaction, Pour point.

\section{INTRODUCTION}

India is a country with a huge population. It imports fossil fuels from other countries to fulfill energy demand which is increasing with increasing population [1]. Energy is in high demand in today's world. Most of the demand was fulfilled previously by fossil fuels but as they are non-renewable in nature, research started in non-renewable energy sector. Diesel is used in vehicles for transportation, mining, etc. However, conventional petroleum products contain a mixture of chemicals of different hydrocarbon chains out of which many are hazardous to environment. Biodiesel can be used to meet this energy requirement without harming the environment. It is made from animal fats or vegetable oil with the help of alcohol (mainly methanol or ethanol). Biodiesel can help us in solving many environmental problems and thus it is very important to study it properly. Researchers realized the scope of biofuels in late 1940 [2]. In this study, we have produced biodiesel from neem oil and have studies its various properties. Neem biodiesel is obtained from neem seeds which contain oil and gets its energy from the bonds in fatty acid methyl esters. Biodiesel can be obtained from various sources such as neem, Jatropha curcas, soybean, and cottonseed. Biodiesel can be used in diesel engines directly without any modification to it [3].

\section{MATERIALS AND METHODS}

\section{Azadirachta indica (Neem)}

Scientific name of neem is " $A$. indica." Neem belongs to the mahogany family, Meliaceae. It is deciduous, that is, it sheds its leaves during the dry winter months. Neem trees are very common in India and are also found in Bangladesh, Nepal. It is a fast-growing tree and valued as a medicinal plant. It is also a source of organic pesticides and also used for its timber.

Neem trees can reach up to 15-25 $\mathrm{m}$ in height. It has a thick furrowed bark. Neem seeds contain about $30-45 \%$ oil in them which is converted to biodiesel for use.

\section{Other uses of neem}

Neem also shows a significant role in prevention of various diseases. It has complex of nimbin, nimbolide, and various other constituents which help in disease management by modulating various pathways. Quercetin is one of the polyphenolic flavonoids which are purified from leaves of neem and it is known to have antibacterial properties.

\section{Chemistry of neem seed}

- $\quad$ Moisture - $15 \%$

- $\quad$ Lipid - $46.4 \%$

- Protein - $19.44 \%$

- Carbohydrate - $17.16 \%$

- Ash - 2\%

Oil is a major component of neem seeds. Unsaturated fatty acid content in neem seed is about $67.07 \%$ and saturated fatty acid content is about $31.70 \%$ [4].

\section{Neem biodiesel production}

Neem biodiesel production system involves neem plant cultivation, extraction of oil from the seeds obtained from neem plant, and then production of neem biodiesel from its oil by transesterification process.

\section{Plantation of neem}

It can be propagated both by seeds or methods of vegetative propagation such as cuttings and grafting. Neem fruits are shown in Fig. 1, which can be used for plantation of neem. A 5-6-month-old seedling can be transplanted in pit size of dimensions $30 \mathrm{~cm} \times 30 \mathrm{~cm} \times 30 \mathrm{~cm}$ during monsoon season. Spacing of about $5 \mathrm{~cm} \times 5 \mathrm{~cm}$ should be present for proper growth. Various properties of neem plant are mentioned in Table 1.

\section{Neem biodiesel}

Neem seeds are processed to produce biodiesel after being harvested. First, seeds are treated to give oil which is later used to produce biodiesel. Oil extraction can be done by the following two methods [3]. 
- First one is chemical extraction. By this method, greater amount of oil can be extracted than that from mechanical extraction. In this, a solvent is used and generally n-hexane is used for this since most oils are soluble in hexane. This method can extract about 95-98\% oil and due to this it is used for producing biodiesel on a large scale. Different solvents give different amount of extracted oil. This method also has some disadvantages like large amount of generated wastewater and also emissions of volatile compounds which affect human health.

- The second is mechanical extraction. It is the traditional method of oil extraction in which mechanical pressers and expellers are used. It is very simple method and does not cost much. In this also, two types of presses can be used. First is manual press in which less amount of oil about $60-65 \%$ is extracted [5]. This is generally used for smallscale production. Another is engine-driven press in which relatively higher percentage of oil is extracted. Seeds and kernels are fed in the extractor and about 70-80\% oil can be extracted by this method. Fatty acid composition of the neem oil is given in Table 2 [4].

\section{Theory}

\section{Experimental setup}

The experimental setup contains a flask of volume of about $1 \mathrm{~L}$. This flask has three-neck round openings in which thermometer, condenser, and stirrer are inserted. The stirrer is inserted in the central neck to continuously agitate the mixture of flask. The flask is dipped in water bath to maintain constant temperature and relay and thermometer is used. Neem oil, methanol/ethanol, and sodium hydroxide $(\mathrm{NaOH})$ are used for producing neem biodiesel. Experimental setup for neem biodiesel production is shown in Fig. 2 [6]

\section{Raw materials and chemicals used}

- Neem oil which is extracted from seeds should not have any sediments, impurities, it should be clear and should not have water. To achieve this, first, oil should be filtered.

- $\quad \mathrm{NaOH}$ taken should be pure and should be water free to avoid unwanted side reactions. It should not be exposed to air as it reacts vigorously with atmospheric air and can even catch fire so it should be stored in airtight containers.

- Alcohol should also be free from water and sediments. It should be stored under lock and key and its density should not exceed 0.79.

- Demineralized water is preferred for this purpose. Water soaks up methanol, releasing impurities to be washed away with water. Water taken should have a $\mathrm{pH}$ of 7.

\section{Methods for producing biodiesel}

There are four ways to use vegetable oils in diesel engines -

1- Blending

2- Transesterification reaction of oil with alcohol on base catalyst

3- Thermal cracking

4- Microemulsification

At present, base-catalyzed reaction is preferred for biodiesel production because-

(i) It occurs at a low pressure of about $20 \mathrm{psi}$ and low temperature range of $55-65^{\circ} \mathrm{C}$.

(ii) By this method, we can get higher yield in minimum time.

Basically, for oils having lower amount of free fatty acids, base-catalyzed reaction is preferred as it gives higher conversion in lesser time for them.

For oils having higher free fatty acids, acid-base catalyst in double-stage process is used.

\section{Chemistry of the process used here}

\section{Transesterification reaction}

It is the most popular way to use vegetable oils and was conducted as early as 1853 by Duffy and Patrick [7]. For soap production, this process was developed in the 1940s for improving glycerine separation [8].
Table 1: Characteristics of neem plant

\begin{tabular}{ll}
\hline English Name & Neem \\
Scientific name & Azadirachta indica \\
Vernacular name & Bevu, Nimba, Vepu, Tamaka \\
Flowering season & March-May \\
Harvest season & June-November \\
Yield starts at (years) & 8 \\
Oil (\%) & $30-50$ \\
Seed yield (kg) & $20-40$ \\
\hline
\end{tabular}

Source: ICAR - Central Agroforestry Research Institute, Jhansi, India

Table 2: Fatty acid composition of neem oil [4]

\begin{tabular}{lc}
\hline Fatty acid & Percentage \\
\hline Oleic acid & 46.85 \\
Linoleic acid & 19.21 \\
Linolenic acid & 0.90 \\
Palmitic acid & 15.57 \\
Stearic acid & 14.50 \\
\hline
\end{tabular}

Table 3: Comparison between various properties of neem oil, neem biodiesel, and conventional diesel

\begin{tabular}{llll}
\hline Properties & Neem oil & Neem biodiesel & Diesel \\
\hline $\begin{array}{l}\text { Density, g/cc } \\
\text { Pour point, }{ }^{\circ} \mathrm{C}\end{array}$ & 0.915 & 0.65 & 0.841 \\
$\begin{array}{l}\text { Calorific value, } \\
\text { MJ/kg }\end{array}$ & 27 & 13 & 9 \\
$\begin{array}{l}\text { Acid value } \\
\text { (in mg KOH/g) }\end{array}$ & 3.52 & 38.14 & 42 \\
$\begin{array}{l}\text { Cetane value } \\
\text { Iodine value }\end{array}$ & 51.09 & 5.32 & Not determined \\
$\begin{array}{l}\text { Saponification } \\
\text { value }\end{array}$ & 101.05 & 90.35 & 50 \\
$\begin{array}{l}\text { Kinematic } \\
\text { viscosity at }\end{array}$ & 25 & 163.2 & Not determined \\
$\begin{array}{l}35^{\circ} \mathrm{C} \text {, in cSt } \\
\text { Flash point, }{ }^{\circ} \mathrm{C}\end{array}$ & 241 & 5.9 & Not determined \\
\hline
\end{tabular}

It is chemical reaction between triglycerides and alcohol (usually methanol or ethanol) in presence of a catalyst to give alkyl esters. Glycerol is also produced in this reaction. Properties of these esters and that of diesel are quite comparable.

Triglyceride + Methanol Glycerol + Methyl esters

Or

Triglyceride + Ethanol Glycerol + Ethyl esters

Temperature of $55-65^{\circ} \mathrm{C}$ is needed for equilibrium conditions. Temperature is kept below the normal boiling point of methanol $\left(65^{\circ} \mathrm{C}\right)$ in most cases so that it is not needed to pressurize the reactor $[9,10]$. At first, it is necessary to make oil free from fatty acids as various undesirable side reactions can take place due to them. Neutralization reaction helps to achieve this.

Chemical reaction taking place is-

$$
\mathrm{RCOOH}+\mathrm{NaOH} \mathrm{RCOONa}+\mathrm{H}_{2} \mathrm{O}
$$

Extracted dehydrated oil is first mixed with $\mathrm{HCl}$ then after sometime about $0.85 \mathrm{~g} \mathrm{NaOH}$ per $100 \mathrm{ml}$ is added to neutralize free fatty acids present. Then, mixture is filtered to remove them. It is necessary to remove FFAs so that saponification reaction does not take place. However, still even after this process, some percentage of FFAs remain in the oil.

Free fatty acid content is determined by titrating sample against $\mathrm{NaOH}$.

Percentage of free fatty acids present can be calculated by- 


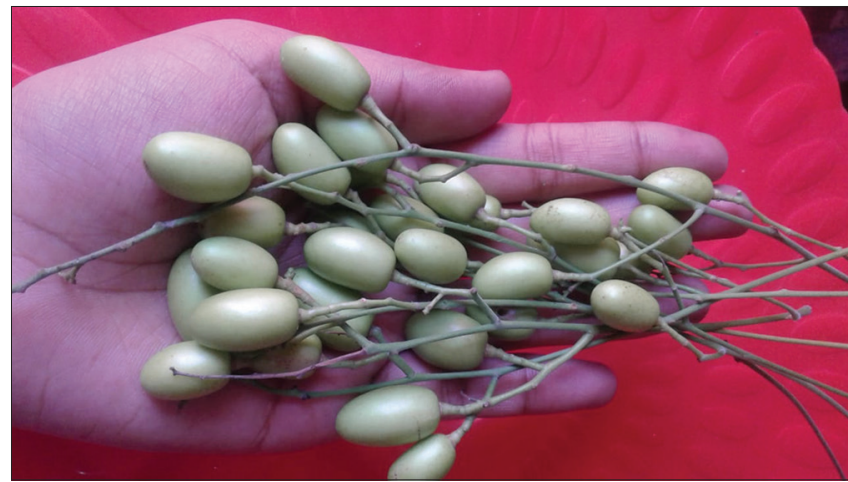

Fig. 1: Neem fruits

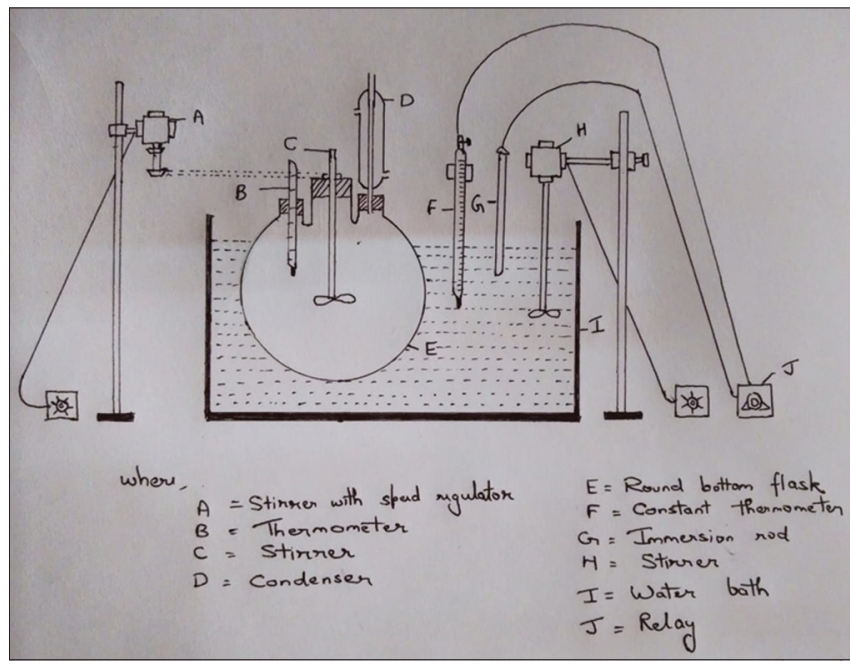

Fig. 2: Experimental setup for neem biodiesel production [6]

Free fatty acid $-(27.8 * \mathrm{~V} * \mathrm{~N}) / \mathrm{W}$

Where $\mathrm{V}$ is $\mathrm{NaOH}$ used in $\mathrm{mL}$

$\mathrm{N}$ is normality of $\mathrm{NaOH}$ solution

$\mathrm{W}$ is weight of neem oil

Amount of methanol/ethanol and catalyst required-

The amount of methanol/ethanol and catalyst used in this present study of preparation of methyl/ethyl ester from oils by transesterification reaction is calculated on the basis of formulae given by author [11].

Formula is

$$
\mathrm{MeOH} \text { required }(\text { in } \mathrm{L})=0.225 * \text { oil }
$$

and potassium hydroxide $(\mathrm{KOH})$ required $=$ oil $/ 100$

oil is amount of non-edible/vegetable oil in L used in the reaction.

Various properties have been determined by different experiments in our study. Determined properties are listed below -

\section{Acid value}

Acid value is also known as neutralization number. It tells the amount of $\mathrm{KOH}$ which is required to neutralize one gram of chemical compound taken.

$$
\text { Acid value }=\left(\mathrm{V}_{\text {eq }} * \mathrm{~N} * 56.1\right) / \mathrm{W}_{\text {oil }}
$$

Where, $\mathrm{W}_{\text {oil }}$ is mass of biodiesel taken in grams

$\mathrm{V}_{\text {eq }}$ is volume of titrant which is consumed by biodiesel (in ml)

$\mathrm{N}$ is normality of $\mathrm{KOH}$ solution taken

It is a measure of number of carboxylic groups in a chemical compound.

\section{Cetane number}

It is a parameter associated with ignition delay time of fuels in a diesel engine. Cetane number scale is based on ignition properties of two hydrocarbons - one is hexadecane having cetane number 100 and other is heptamethylnonane having cetane number 15. Fuel having higher cetane number has better ignition properties.

Cetane number $=\%$ n-cetane $+0.15 *(\%$ heptamethylnonane $)$

\section{Iodine value}

Iodine value is a measure of degree of unsaturation in oil. It is measured by determining the amount of iodine (in grams) which is absorbed by $100 \mathrm{~g}$ of oil sample. Compound having higher iodine value will be more unsaturated and thus less stable.

$$
\text { Iodine number }=\{12.69 *(\mathrm{~B}-\mathrm{S}) * \mathrm{~N}\} / \mathrm{W}
$$

Where $\mathrm{N}$ is the normality of standard thiosulfate solution

$\mathrm{W}$ is weight in grams of the taken compound for test

$\mathrm{B}$ is volume of standard thiosulfate solution for the blank (in ml)

$\mathrm{S}$ is volume of standard thiosulfate solution for sample (in $\mathrm{ml}$ )

\section{Saponification value}

It corresponds to the mass of $\mathrm{KOH}$ in mg which is required to neutralize free fatty acids and saponify $1 \mathrm{~g}$ of oil. Saponification value of neem oil is 195.5. Oils which have high saponification value impart high foamability as then production of soap will be more.

$$
\text { Saponification value }=\{56.1 *(B-S) * N\} / W
$$

Maximum yield can be obtained by carrying out the reaction at standard conditions. Warm water is generally used in washing to obtain biodiesel which is free from glycerine.

\section{Viscosity}

It is the internal resistance or friction between different fluid layers of oil. It is a measure of resistance to flow and can be determined by redwood viscometer. Formula to determine kinematic viscosity is,

$$
\mathrm{v}=\mathrm{A} * \mathrm{t}-\mathrm{B} / \mathrm{t}
$$

Where, $\mathrm{t}$ is efflux time in seconds

A is calibration constant of instrument and B is instrument type constant

\section{Flash point}

t is an important property for storage and handling of a fuel. It is the lowest temperature at which the fuel will form enough vapor around it that will ignite the oil and produce flame. To determine flash point of fuel, Abel and Pensky-Martens apparatus are used.

\section{Density}

It can be defined as mass per unit volume. It can be measured with an apparatus called hydrometer. Denser oils have more energy in them. 


\section{Calorific value}

It is the amount of heat produced or energy released when a unit amount of fuel is burnt completely in presence of oxygen. It tells about the energy content of fuel.

\section{Pour point}

It is the temperature at which a liquid cease to flow hence becomes semi-solid. ASTM D5853 test is used to measure pour point. Higher pour point indicates higher paraffinic content. Because of this paraffin in oil, precipitation begins when temperature is brought down to a certain level. In this test, chemical specimen is put inside a cooling bath and left to form paraffin wax crystals. When the temperature becomes about $9^{\circ} \mathrm{C}$ above expected pour point, then surface movement of specimen is checked for every $3^{\circ} \mathrm{C}$. If specimen does not flow, then pour point is equal to $3^{\circ} \mathrm{C}$ added to the respective temperature.

\section{RESULTS AND DISCUSSION}

Various fuel properties of neem biodiesel that are determined in our study are compared with properties of conventional diesel fuel in Table 3. We have seen in our study that pour point of neem biodiesel is larger than that of diesel and because of this performance of neem biodiesel in cold conditions reduces [12]. Viscosity is also a very important property of fuel. Fuels having viscosity higher than the standard value can lead to clogging in the fuel engine. We have seen that the kinematic viscosity of neem oil is high, due to which we cannot use it directly into engines. Furthermore, the value of kinematic viscosity decreases with the increase in temperature.

As the flash point of neem oil and its biodiesel is much high compared to that of diesel, the hazard due to flammability of neem oil and its biodiesel is lesser.

Cetane number is measure of ignition quality of fuel. Hence, the performance is greatly affected by cetane number. If it is high, then the fuel will ignite in a very short period and will show incomplete combustion as then air and fuel will not be able to mix completely. If fuel has high density, then it will be difficult to pump it in engine. Properties of obtained neem biodiesel are similar to results obtained by other researchers [13].

Most of the fuel properties of neem biodiesel were within the permissible limits and they can be compared to that of conventional diesel fuel.

\section{CONCLUSION}

We have seen that neem biodiesel is a good alternative to the conventional fuel.

First, free fatty acid content of oil is reduced and then the alkaline catalyst transesterification converted it into alkyl esters and glycerol. Neem biodiesel has high viscosity. Transesterification reaction used in production of neem biodiesel has given good yields and in this reaction, glycerine is also obtained which is used in cosmetic industries and other.

Its density is high and the biodiesel obtained has some properties similar to that of conventional diesel.

\section{REFERENCES}

1. Tiwari S, Verma PC, Tuli PK. Plants as bioreactors for the production of vaccine antigens. Biotechnol Adv 2009;27:449-67.

2. Bradshaw GB. New soap process. Soap 1942;23-24:69-70

3. Axelsson L, Franzén M. Performance of Jatropha Biodiesel Production and its Environmental and Socio-economic Impacts. A Case Study in Southern India; 2010

4. Attia NY, Abd El-Aleem IM, Kamel KM, Saliem NS. Biochemical and environmental studies on Neem Leaves and seed. J Biol Chem Environ Sci 2015;10:373-97.

5. Achten WM, Verchot L, Franken YJ, Mathijs E, Singh VP, Aerts R, et al. Jatropha bio-diesel production and use. Biomass Bioenergy 2008;32:1063-84

6. Kumari S, Kaur V, Kumar A, Singh TP. Studies on biodiesel: A plant oil based renewable fuel. World J Pharm Pharm Sci 2016;5:1275-88.

7. Ma F, Hanna MA. Biodiesel Production: A review. Bioresource Technol 1999;70:1-15.

8. Bradshaw GB, Meuly WC. Process of Making Pure Soaps, U.S. Patent No. 2,271,619; 1942

9. Van Gerpen JH, Peterson CL, Goering CE. Biodiesel: An Alternative Fuel for Compression Ignition Engines, for presentation at the 2007 Agricultural Equipment Technology Conference Louisville, Kentucky, USA 11-14 February; 2007.

10. Van Gerpen J. Biodiesel processing and production. Fuel Proc Technol 2005;86:1097-107.

11. Peterson CL, Reece DL, Hammond BJ, Thompson J, Beck SM. Processing, Characterization and Performance of Eight Fuels from Lipids, ASAE International Winter Meeting, Paper No. 946531; 1994.

12. Peterson C, Reece D. Emissions characteristics of ethyl and methyl ester of rapeseed oil compared with low sulfur diesel control fuel in a chassis dynamometer test of a pickup truck. Trans Am Soc Agric Eng 1996;39:805-16.

13. Ali MH, Mashud M, Rubel MR, Ahmad RH. Biodiesel from Neem oil as an alternative fuel for Diesel Engine. Proc Eng 2013;56:625-30. 